\title{
Design and Development of Audio Data Transmission Using Visible Light Communication
}

\author{
Catur Budi Waluyo *,a,1, Benedictus Mardwianta ${ }^{\text {b,2 }}$, Oswald Richfild Tambunan ${ }^{\text {a,3, }}$, Lasmadi a,4 \\ a Department of Electrical Engineering, Sekolah Tinggi Teknologi Adisutjipto, Yogyakarta, Indonesia \\ ${ }^{\mathrm{b}}$ Department of Mechanical Engineering, Sekolah Tinggi Teknologi Adisutjipto, Yogyakarta, Indonesia \\ ${ }^{1}$ catur_budiwaluyo@yahoo.co.uk*,2 aries2144@yahoo.com, ${ }^{3}$ oswaldtambunan77@gmail.com, \\ ${ }^{4}$ lasmadi@stta.ac.id
}

\begin{abstract}
The developments of technology have opened up new infrastructure in communication for transmitting audio data. This is evidenced by a large number of communication media, both wired and wireless. Hence, it raises new methods for sending audio data, one of which is using Visible Light Communication (VLC). VLC is a communication system for transmitting and receiving data using the visible light wave spectrum between $375 \mathrm{~nm}$ - $780 \mathrm{~nm}$. In this research, audio data communication utilizes the brightness of the LED light. The transmitter and receiver use an LED component as a transducer which is then sent to the data processing circuit. The data processing circuit is then sent to the audio amplifier circuit. From the test results, it can be shown that this system can transmit audio data. Based on the LED color test, Green produces the highest output voltage of 1.32 Volt. The angle limit that can be detected by the photodiode is at an angle of $70^{\circ}$ with a measured voltage of $100 \mathrm{mV}$ and the resulting sound intensity of $-32.541 \mathrm{~dB}$
\end{abstract}

Keywords: VLC, LED, Communication, Audio

\section{INTRODUCTION}

The development of wireless technology has opened a new infrastructure in communication for transmitting audio data. This is evidenced by the new technology for transmitting audio data using Visible Light Communication (VLC). VLC is a communication system for transmitting and receiving data using the visible light wave spectrum between 375 $\mathrm{nm}$ - $780 \mathrm{~nm}$ [1],[4],[6]. This technology works at visible light frequencies. The working principle is almost the same as the frequency of radio waves which can transmit data without disturbing humans and can be used anywhere and anytime. The necessity to develop an additional wireless communication technology is the result of the almost exponential growth in the demand for high-speed wireless connectivity [11][12].

The transmission technique in this communication system uses an LED (Light Emitting Diode) with speeds up to 224Gbps [2] [3]. In VLC technology, Light Emitting Diode (LED) is used as a transmitter, and a photodetector is used as a receiver [8]. VLC technology works at a frequency of $400-800 \mathrm{THz}$ which supports multi-user access, handover and minimizes interference [6]. Therefore, this research will design a prototype for sending audio data using VLC.

In this research, audio data from the computer is sent using an LED, then received by the photodiode, and the demodulation process was carried out and converted into sound signals using a speaker. A measurement for the components and color of the LEDs is used, as well as the angle of emission between the transmitter and receiver.

\section{ThEORETICAL BASIS}

\section{A. Visible Light Communication}

Visible Light Communication (VLC) is a communication system for transmitting and receiving data information using visible light by utilizing a wavelength of $380 \mathrm{~nm}$ - $780 \mathrm{~nm} \mathrm{[1].} \mathrm{In} \mathrm{VLC}$ technology, Light Emitting Diode (LED) is used as a transmitter and a photodetector is used as a receiver [8],[9],[10]. The light emitted from the LED is received by the photodiode, then the demodulation process is carried out. After that, the received signal is amplified by using the NPN BC547BP BJT (Bipolar Junction Transistor) amplifier circuit. In the VLC circuit, this component is used as a low noise audio amplifier driver stage. The electrical signal output from the amplifier is then converted into sound using speakers. The block diagram of VLC technology can be seen in Figure 1 [4].

The Electromagnetic (EM) spectrum consists of gamma waves, X, Ultra Violet (UV), Visible light, Infra-Red (IR), Micro Waves (MW), and Radio Waves (RW), as shown in the Figure. 2. Gamma radiations (rays) are not generally used. X-rays are used in hospitals. UV-rays are harmful to the human body. Visible light is almost the same as radio waves that can be used to transmit data. Visible light is not harmful to human beings and is available easily everywhere and anywhere [4]. 

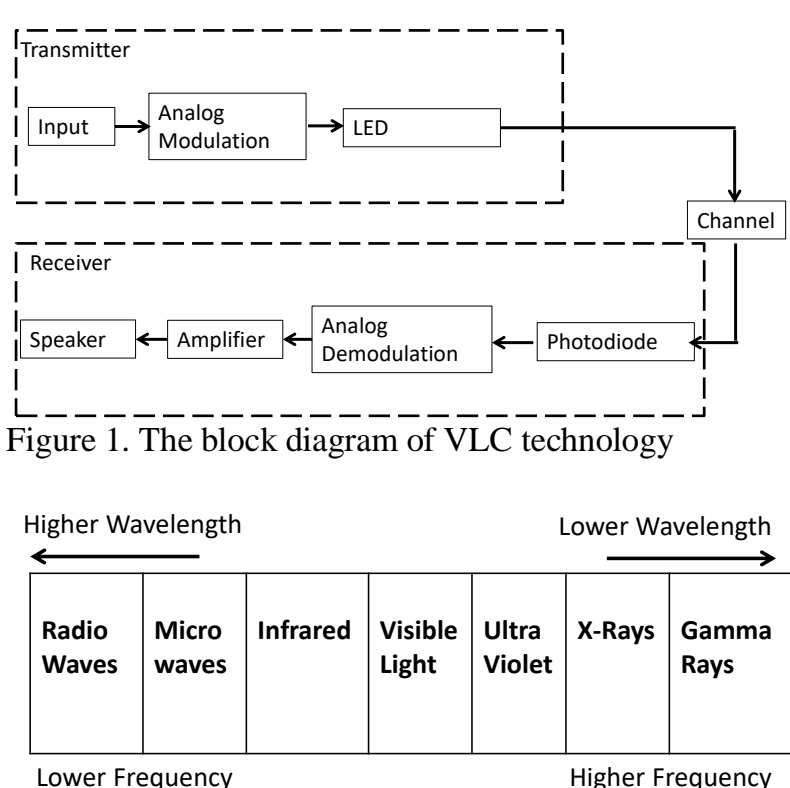

Figure 2. The Electromagnetic (EM) Spectrum[4][5]

\section{B. Light Emitting Diodes (LED)}

LEDs are electronic components that can emit monochromatic light when they are subjected to a forward voltage. In current technological developments, LEDs offer more space for setting parameters of lighting, color, correlated color temperature (CCT), white color rendering, and light spectrum [7]. LEDs are a type of diode made of semiconductor materials. The color of the light emitted by an LED depends on the type of semiconductor material used. LEDs can also emit invisible infrared light which is often used on TV remotes.

\section{Photodiode}

A photodiode is a diode that is sensitive to light. The photodiode sensor will experience a change in resistance when receiving light intensity and will flow the electric current forward as a diode in general. Photodiode will flow currents which form a linear function of the intensity of light received. This current is generally regular concerning power density. The ratio between the output current and the power density is known as current responsitivity. The current in question is the leakage current when the photodiode is irradiated and in a backward biased.

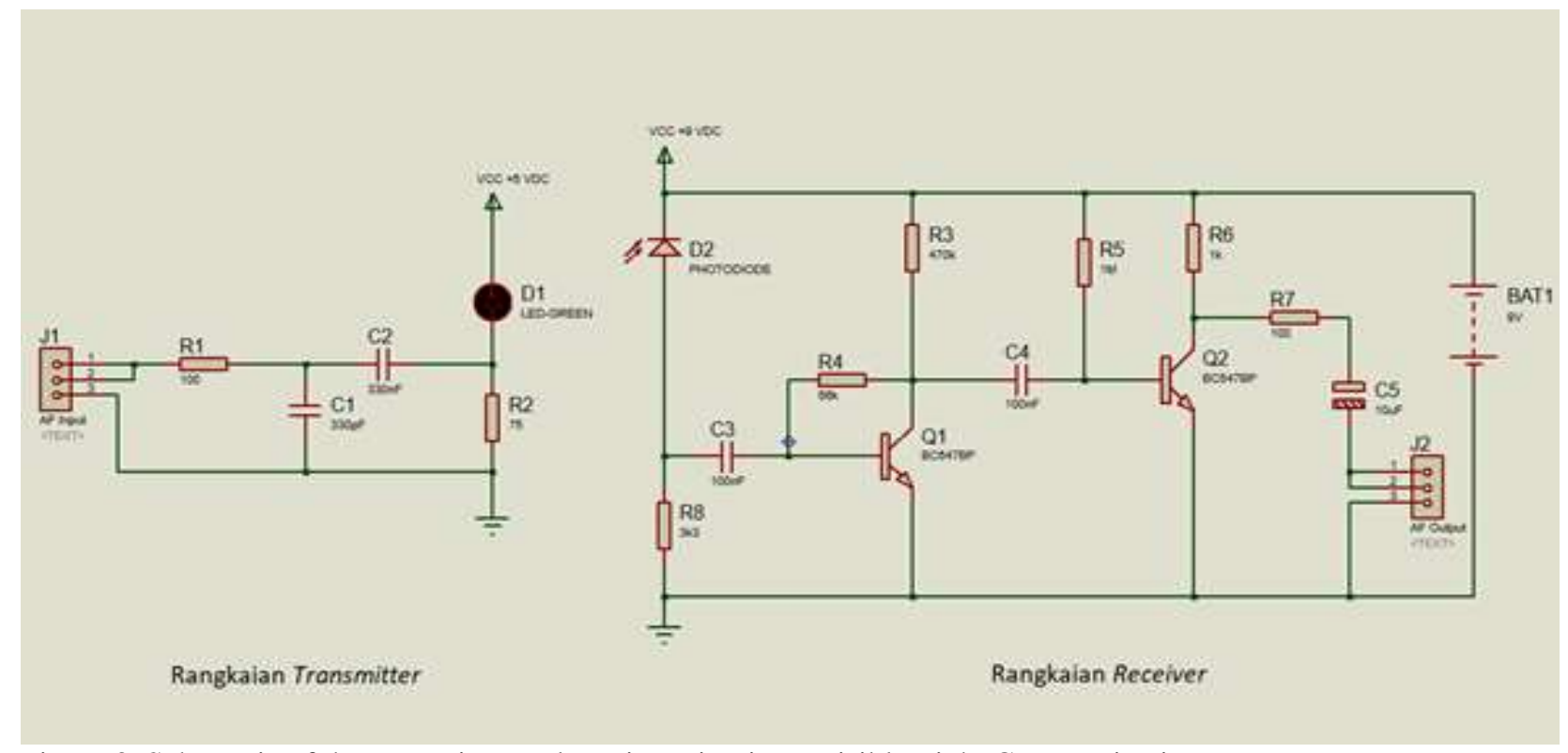

Figure 3. Schematic of the transmitter and receiver circuit on Visible Light Communication

\section{SYSTEM DESIGN}

The design in this research consists of the transmitter and receiver. The components used in the design of the transmitter include 2 resistors, 2 capacitors, and a LED. While the components on the receiver include: photodiode, 3 capacitors, 6 resistors, and 2 transistors. The schematic of the transmitter and receiver circuit for communication via VLC is shown in Figure 3. As for the test block diagram, it can be seen in Figure 4.

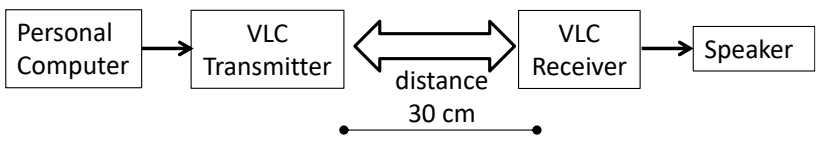

Figure 4.VLC circuit test diagram 


\section{RESULT AND DISCUSSIONS}

\section{A. Testing the Circuit}

The measurement of the transmitter circuit is given a voltage of 5 volts and a current of $2 \mathrm{~A}$. In this case, the LED is conditioned to emit and transmit a signal through the LED light. The light transmit can be received by the photodiode as a light sensor in the receiver circuit. The distance between the Transmitter and Receiver is kept at $50 \mathrm{~cm}$, using the Function generator as a $500 \mathrm{~Hz}$ sine wave input signal generator and using an oscilloscope so that the signal waveform can be seen in Figure 5.

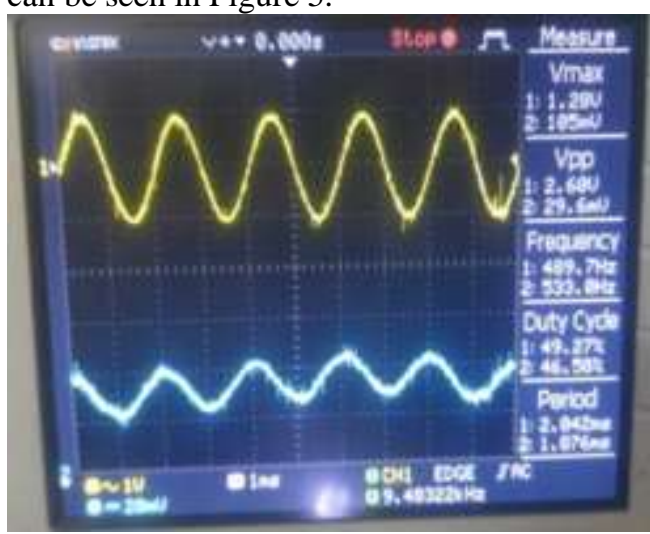

Figure 5. Measurement results on the oscilloscope on the Transmitter circuit

At the receiver, the BC547BP transistor is used to amplify the signal received by the photodetector. The results of measuring the output signal on the oscilloscope with the Function Generator input signal are presented in Figure 6.

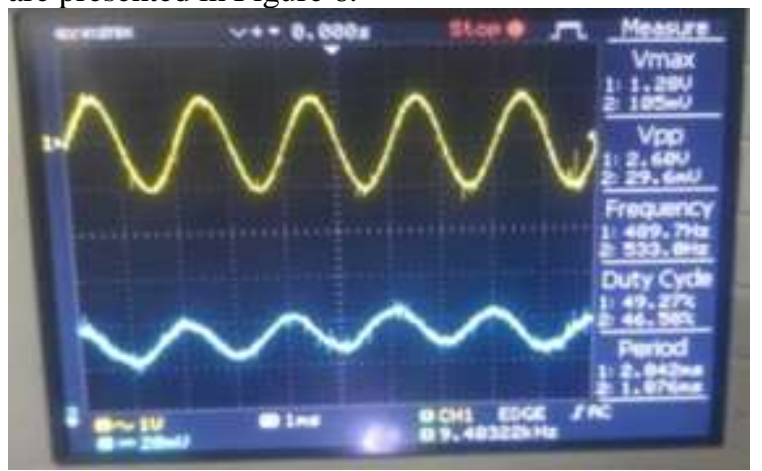

Figure 6. Measurement results on the oscilloscope on the Receiver circuit

\section{B. Testing of LED Color}

This test of LED color type is carried out to determine the characteristics of the LED components that will be used. The test scheme can be seen in Figure 4. Testing was done by replacing the LED component in the transmitter section then measuring the voltage both input and output in the transmitter and receiver parts. At the time of this test, the transmission distance is $30 \mathrm{~cm}$ and the device is conditioned to transmit audio data to the receiver. The results of measuring the type of LED color used can be seen in Table 1.
TABLE I. THE MEASUREMENT RESULTS FOR THE TYPE OF LED COLOR USED

\begin{tabular}{|l|c|c|}
\hline Color & Input Voltage & Output Voltage \\
\hline Red & 2.24 Volt & 1.04 Volt \\
\hline Blue & 2.48 Volt & $960 \mathrm{mVolt}$ \\
\hline Yellow & 2.56 Volt & 1.00 Volt \\
\hline Green & 2.32 Volt & 1.32 Volt \\
\hline White & 2.40 Volt & $60.00 \mathrm{mVolt}$ \\
\hline
\end{tabular}

Based on the LED color test results in Table 1, it can be seen that the green color produced the highest output voltage of 1.32 volts. While the white LED color produced the lowest output voltage.

\section{Measurement on the beam angle}

The beam angle test is carried out to determine the optimal angle shift in audio data transmission with VLC. This test is carried out by moving the receiving device according to a predetermined angle $0^{\circ}, 20^{\circ}, 40^{\circ}$, $70^{\circ}$, and $90^{\circ}$. The test scheme can be seen in Figure 7. In the $0^{\circ}$ test, the position of the transmitter and receiver is straight Line of Sight (LOS) and the position of the receiver is marked as letter A. Meanwhile, in the second test, the position of the receiver is shifted by $20^{\circ}$ and is marked as letter B. Angle measurement can be seen in Table 2. Based on Table 2 it can be seen that the measurement results at a $90^{\circ}$ angle shift, audio data transmission fails and cannot be detected by the photodiode. Maximum results are obtained when the LEDs on the transmitter and receiver are not shifted or the angle is $0^{\circ}$.

Based on Table 2, it can also be seen that the angle limit that can be detected by the photodiode is at an angle of $70^{\circ}$ with a measured voltage of $100 \mathrm{mV}$ and the resulting sound intensity of $-32.541 \mathrm{~dB}$.

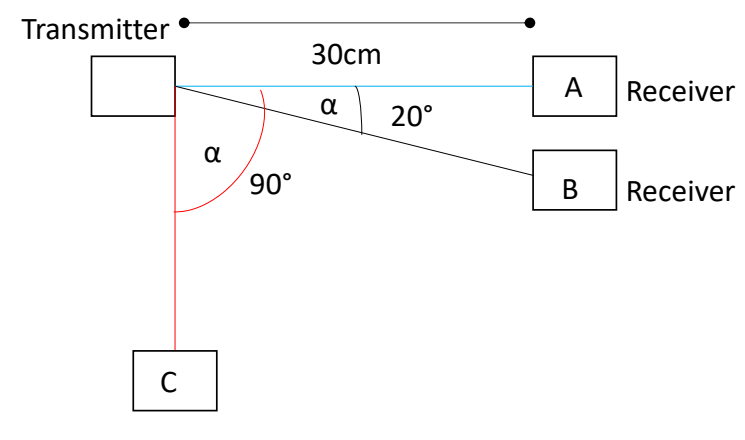

Receiver

Figure 7. Schematic of beam angle test

TABLE II. RESULTS OF ANGLE MEASUREMENTS ON VLC.

\begin{tabular}{|c|c|c|}
\hline Angle & $\begin{array}{c}\text { Output Voltage } \\
{[\mathrm{mVolt}]}\end{array}$ & $\begin{array}{c}\text { Sound } \\
\text { Intensity }\end{array}$ \\
\hline $0^{\circ}$ & 592 & $-12.879 \mathrm{~dB}$ \\
\hline $20^{\circ}$ & 510 & $-13.555 \mathrm{~dB}$ \\
\hline $40^{\circ}$ & 120 & $-26.935 \mathrm{~dB}$ \\
\hline $70^{\circ}$ & 100 & $-32.541 \mathrm{~dB}$ \\
\hline $90^{\circ}$ & - & - \\
\hline
\end{tabular}




\section{Conclusion}

In the design of VLC-based data transmission, the components used in the transmitter section consist of 2 resistors, 2 capacitors, and 6 LEDs. While the components in the receiver section consist of 6 resistors, 3 capacitors, 6 photodiodes, and 2 transistors. Based on the LED color type test, the green color produced the highest output voltage of 1.32 volts. While the white LED produced the smallest output voltage. The limit of the tilt angle that can be detected by the photodiode, which was at the angle of $70^{\circ}$ with a measured voltage of $100 \mathrm{mV}$ and the resulting sound intensity of $-32.541 \mathrm{~dB}$

\section{ACKNOWLEDGMENT}

We would like to thanks Sekolah Tinggi Teknologi Adisutjipto for the 2019 research grant.

\section{REFERENCES}

[1] Sandip Das, Ankan Chakraborty, Debjani Chakraborty, Sumanjit Moshat, "PC to PC Data Transmission using Visible Light Communication", 2017 International Conference on Computer Communication and Informatics (ICCCI -2017), Jan. 05 - 07, 2017, Coimbatore, INDIA, IEEE

[2] Debanjana Ghosh, Soumyajit Chatterjee, Vasudha Kothari, Aakash Kumar, Mahesh Nair, Ella Lokesh, "An application of Li-Fi-based Wireless Communication System using Visible Light Communication". 978-1-7281-0070-8/19/, 2019, IEEE

[3] D. Aguirre, R. Navarrete, I. Soto, and S. Gutierrez, Implementation of an emitting LED circuit in a Visible Light Communications positioning system, 78-1-5386-1782-3/17, 2017, IEEE

[4] Mithileysh Sathiyanarayanan, Vignesh Govindraj, Nandakishor Jahagirdar, "Challenges and Opportunities of Integrating the Internet of Things (IoT) and Light Fidelity
(LiFi)", 978-1-5386-1144-9, International Conference on Applied and Theoretical Computing and Communication Technology pp 137-142, 2017, IEEE

[5] Deepali Javale, Sujata Wakchaure, Sahil Santosh Patil, Chinmay Atul Sashittal, Ameya Milind Phadnis, Rohan Sanjay Shahane, "A new approach to wireless data transmission using visible light", 2018 Fourth International Conference on Computing Communication Control and Automation (ICCUBEA), 978-1-5386-5257-2/18, 2018, IEEE

[6] Hieu Danh Huynh \& Kumbesan Sandy Sandrasegaran, "Coverage Performance of Light Fidelity (Li-Fi) Network", 2019 25th Asia-Pacific Conference on Communications (APCC), 978-1-7281-3679-0/19, pp: 361-366, 2019, IEEE

[7] Tianhang Zheng, Wujun, Zhixian Zhou, Wanghui Yan, "Smart Lighting with Autonomous Color Tunability", 978-1-72815756-6/19, pp: 256-259, 2019, IEEE

[8] Anand Singh, Yash Gupta, Ashutosh Bansal, Anand Srivastava, Vivek Ashok Bohara and Anand Kumar Jagadeesan, "A Smart User-Centric Visible Light Communication System", ICTON 2020, 978-1-7281-84234/20, pp: 1-5, 2020, IEEE

[9] Ning WANG, Yang QIAO, Wuqu WANG, Suheng TANG, and Jianhua SHEN, "Visible Light Communication based Intelligent Traffic Light System: Designing and Implementation", 2018 Asia Communications and Photonics Conference (ACP), 978-1-5386-6158-1/18, 2018, IEEE

[10] Doohee Han and Kyujin Lee, "High-Speed Parallel Transmission Visible Light Communication Method with Multiple LED Matrix Image Processing Technique", ICUFN 2019, pp: 576- 580, 2019, IEEE

[11] C.B. Waluyo and iskandar, "Performance analysis with LMMSE for MIMO LTE on the High Altitude Platform Station," ICEEI 2015 proc pp 308 - 313. IEEE. 2015.

[12] S. Arnon, Visible Light Communication, First Edition. United Kingdom: Cambridge University Press, 2015. 